\title{
Risk of low back pain in people admitted to hospital for traffic accidents and falls
}

\author{
Kevin Walsh, Marie Cruddas, David Coggon
}

\begin{abstract}
Study objective-The aim was to assess the risk of back symptoms in people admitted to hospital because of traffic accidents and falls.

Design-The study was a cross sectional survey with information collected by postal questionnaire. Main outcome measures were associations between hospital admission for a traffic accident or fall and reported first onset of back symptoms at the same age and at later ages.

Setting-General practices in seven towns and one rural district.

Subjects-1172 men and 1495 women aged 20-59 years were selected from the age-sex registers of 136 general practitioners in the study areas.

Main results-Low back pain was reported by 1556 subjects and hospital admission for a traffic accident or fall by 362 . The incidence of low back pain was unusually high during the year of age at which subjects were first admitted to hospital for trauma $(R R=5.5$, 95\% CI 3.8-7.8). The risk of first developing symptoms in subsequent years was lower, but still significantly increased $(R R=1 \cdot 3$, 95\% CI 1-1-1·6). Low back pain which started at the age of an accident tended to last longer than that occurrring in other circumstances, and was more often ascribed to injury (56\% of cases). However, this proportion was smaller than the calculated attributable proportion for traffic accidents and falls (82\%).

Conclusions-The data suggest that a person under age 60 years who is admitted to hospital for a traffic accident or fall has a $7 \%$ chance of developing low back pain as result of the injury. However, the link between the injury and subsequent symptoms is often not obvious to the patient.
\end{abstract}

Many patients with low back pain attribute their symptoms to an injury, ${ }^{1-3}$ although the onset of symptoms does not always follow the initiating event immediately. Often the suspected trauma takes the form of a sudden unusual load on the spine, for example while lifting. The true impact of such trauma is difficult to assess epidemiologically because the incidents which are alleged to damage the spine are ill defined and may only be identified in retrospect.

More severe trauma leading to hospital admission can be measured more reliably. As part of a survey of low back pain in the general population, we have examined the relation of symptoms to hospital admission for a traffic accident or fall.
Methods

Postal questionnaires were sent to a $5 \%$ random sample of men and women aged 20-59 years, selected from the lists of general practitioners in seven British towns and one rural district. The information sought included any history of hospital admission (for at least one night) for a traffic accident or fall, and the ages at which this had occurred. Subjects were also asked whether they had ever experienced low back pain in an area (indicated on a diagram) between the twelfth ribs and the gluteal folds, which lasted more than a day. Pain occurring only during a feverish illness, menstrual periods, or pregnancy was excluded. Those who reported pain were asked how old they were when it first began; whether the pain had ever spread down the leg below the knee (referred to here as "sciatica"), and if so from what age; whether the onset of pain was sudden or gradual; to what activity or circumstance they attributed the pain; and the approximate total lifetime duration of low back pain. Non-responders were sent a reminder after one month.

Associations between hospital admission for trauma and the onset of low back pain and sciatica were examined by Cox's proportional hazards model with allowance for time dependent covariates. ${ }^{45}$ This gave estimates of relative risk (RR) with $95 \%$ confidence intervals (95\% CI). All analyses took into account the potential confounding effects of sex and year of birth (in four 10 year strata).

Further details of the study sample and method of data collection are reported elsewhere. ${ }^{67}$

\section{Results}

Questionnaires were completed by 1172 men and 1495 women, an overall response rate of $59.2^{\circ}$. Of these, $1556(58.3 \%)$ gave a history of low back pain and $398(14.9 \%)$ of associated sciatica. Three hundred and sixty two subjects reported hospital admission for a traffic accident or fall, including 32 who had been admitted more than once. We excluded from further analysis 46 subjects who did not answer the question about trauma and four who had had an accident, but could not remember at what age.

When analysing associations with low back pain, we also excluded a further 38 subjects whose pain began before age 15 years and 116 who could not recall at what age their symptoms had started. Table I summarises the relation between first hospital admissions for a traffic accident or fall and the onset of low back pain. At the age at which hospital admission occurred there was a fivefold increase in the incidence of low back pain. The risk of new low back pain at later ages was lower,
Accepted for publication June 1991 
but still significantly increased $(R R=1.3,95 \% \mathrm{CI}$ 1.1-1.6). Of the 133 subjects who developed low back pain at an interval after first hospital admission for an accident, only two had suffered a further accident at the age when symptoms began. The relation of risk to trauma was similar in men and in women.

Pain which started at the age of hospital admission for a traffic accident or fall was more likely to be sudden in onset than that occurring in other circumstances, and tended also to be longer in duration (table II). Of the 32 subjects whose low back pain began at the same age as an accident, $10(31 \%)$ reported that their pain had lasted more than 12 months in total. Not surprisingly, many of these men and women attributed their symptoms to the trauma. However, the proportion who did so $(56 \%)$ was less than that expected from the risk estimate in table I $[(5.5-1) / 5.5 \times 100=82 \%]$.

Table III shows associations between first hospital admission for trauma and the onset of sciatica. Risk estimates were similar to those for all low back pain.

\section{Discussion}

In this study victims of traffic accidents and falls severe enough to warrant hospital admission reported a fivefold increased incidence of low back pain during the year of age at which the injury occurred. Two possible sources of error could have inflated this risk estimate.

First, a bias could have arisen from the incomplete response to the questionnaire. Part of the incomplete response was explained by 410 subjects $(9.1 \%$ of the original sample) who had changed address and could not be traced. ${ }^{6}$ It seems unlikely that this loss would have seriously

Table I Risk of incident low back pain according to history of hospital admission for a traffic accident or fall

\begin{tabular}{|c|c|c|c|c|c|c|c|c|c|}
\hline & \multicolumn{3}{|l|}{ Men } & \multicolumn{3}{|c|}{ Women } & \multicolumn{3}{|c|}{ Both sexes } \\
\hline & $n$ & $R R$ & $95 \% C I$ & $n$ & $R R$ & $95 \% C I$ & $n$ & $R R$ & $95 \% C I$ \\
\hline $\begin{array}{l}\text { No previous hospital } \\
\text { admission for traffic } \\
\text { accident or fall at onset } \\
\text { of low back pain. }\end{array}$ & 518 & 1 & & 691 & 1 & & 1209 & 1 & \\
\hline $\begin{array}{l}\text { First hospital admission } \\
\text { for traffic accident or fall } \\
\text { at earlier age than onset of } \\
\text { low back pain. }\end{array}$ & 86 & 1.2 & $1.0-1.6$ & 47 & 1.4 & $1.1-1.9$ & 133 & 1.3 & $1.1-1.6$ \\
\hline $\begin{array}{l}\text { First hospital admission } \\
\text { for traffic accident of fall } \\
\text { at same age as onset of } \\
\text { low back pain }\end{array}$ & 22 & 5.3 & $3.5-8.2$ & 10 & 5.7 & $3.0-10.8$ & 32 & 5.5 & $3.8-7.8$ \\
\hline \multicolumn{10}{|c|}{$\begin{array}{l}\text { The analysis excluded } 46 \text { subjects who did not answer the question about traurna, four who could } \\
\text { not remember at what age their accident occurred, } 38 \text { whose low back pain started before age } 15 \\
\text { years and } 116 \text { who could not remember when their low back pain began. }\end{array}$} \\
\hline \multicolumn{10}{|c|}{$\begin{array}{l}\text { Table II Characteristics of low back pain according to history of hospital admission } \\
\text { for a traffic accident or fall (both sexes) }\end{array}$} \\
\hline & & \multicolumn{2}{|c|}{ Sudden onset } & & \multicolumn{2}{|c|}{$\begin{array}{l}\text { Total duration } \\
>12 \text { months }\end{array}$} & \multicolumn{3}{|c|}{$\begin{array}{l}\text { Onset attributed to } \\
\text { traffic accident or } \\
\text { fall by subject }\end{array}$} \\
\hline & & $n$ & $\%$ & & $n$ & $\%$ & $n$ & & $\%$ \\
\hline $\begin{array}{l}\text { No previous hospital admiss } \\
\text { traffic accident or fall at ons } \\
\text { low back pain }\end{array}$ & $\begin{array}{l}\text { on for } \\
t \text { of }\end{array}$ & 541 & 44.7 & & 278 & 23.0 & 82 & & 6.8 \\
\hline $\begin{array}{l}\text { First hospital admission for } \\
\text { accident or fall at earlier age } \\
\text { onset of low back pain }\end{array}$ & $\begin{array}{l}\text { raffic } \\
\text { than }\end{array}$ & 66 & 49.6 & & 30 & 22.5 & 19 & & 14.3 \\
\hline $\begin{array}{l}\text { First hospital admission for } \\
\text { accident or fall at same age } \\
\text { of low back pain }\end{array}$ & $\begin{array}{l}\text { raffic } \\
\text { s onset }\end{array}$ & 20 & 62.5 & & 10 & 31.3 & 18 & & 56.3 \\
\hline
\end{tabular}

exaggerated risk estimates. Of the remaining 1425 non-responders, 525 replied on a third mailing to an abbreviated questionnaire which asked only about symptoms. ${ }^{6}$ The lifetime prevalence of low back pain in this subset was little different from that in those who completed the full questionnaire $(53.1 \%$ compared with $58.3 \%)$, suggesting that non-responders were not highly atypical. Furthermore, trauma was not a major focus of the questionnaire, most of which was devoted to occupational and recreational activities and to details of symptoms. Nevertheless, we cannot exclude the possibility that some subjects with low back pain selectively responded to the questionnaire because they attributed their illness to an accident. The potential impact of such a bias can be assessed by considering the extreme situation in which the response rate in subjects whose

Table III Risk of incident sciatica according to history of hospital admission for a traffic accident or fall (both sexes)

\begin{tabular}{llll}
\hline & $\begin{array}{l}\text { Number } \\
\text { of cases }\end{array}$ & $R R$ & $95 \%$ CI \\
\hline $\begin{array}{l}\text { No previous hospital admission for } \\
\text { traffic accident or fall at onset of } \\
\text { sciatica }\end{array}$ & 295 & 1 & \\
$\begin{array}{l}\text { First hospital admission for } \\
\text { traffic accident or fall at earlier }\end{array}$ & 47 & 1.5 & $1.1-2.0$ \\
age than onset of sciatica & & & \\
$\begin{array}{l}\text { First hospital admission for } \\
\text { traffic accident or fall at same } \\
\text { age as onset of sciatica }\end{array}$ & 5 & 5.2 & $2.1-12.6$ \\
\hline
\end{tabular}

The analysis excluded 46 subjects who did not answer the question about trauma, four who could not remember at what age their accident had occurred, 24 who did not answer the question about sciatica, two with first sciatica before age 15 years, and 41 who could not remember when their sciatica started.

back pain began at the time of an accident was $100 \%$, while that in other subjects was only $50 \%$. Even in these unlikely circumstances, the response bias would only lead to a doubling of the risk estimate.

A second possibility was that subjects with a history of trauma recalled back symptoms more reliably than those who had not been involved in accidents, for example because of associated litigation. Again, this cannot be completely ruled out, but the high lifetime incidence of low back pain in subjects who had not previously suffered accidents $(49.1 \%)$ suggests that underreporting in this group could only explain a small part of the observed association. Moreover, the excess risk cannot be explained by accident victims dating the onset of their symptoms earlier than other subjects because of better recall. If this were the case, one would expect a corresponding deficit in the reported incidence of low back pain in the years following an accident. In fact there was a significant excess (table I).

Substantial underreporting of accidents by subjects who did not have low back pain seems unlikely since hospital admission is a memorable event.

We did not ask directly whether the onset of symptoms was related to an accident because we were concerned that this would have increased the scope for bias. It follows that when subjects reported trauma and low back pain at the same age, we cannot be sure that the injury preceded the development of pain. However, there is no plausible reason why low back pain should substantially 
increase a person's risk of traffic accidents or falls.

In response to an open question, $56 \%$ of the subjects with first low back pain at the age of a traffic accident or fall ascribed their symptoms to such injury. This is less than the proportion that would be predicted from our risk estimate $(82 \%)$ and suggests that people do not always recognise the relation of their back pain to injury, perhaps because the pain only starts gradually or after a latent interval. It is further evidence that the recorded association of low back pain with accidents cannot be explained simply by a response bias.

Low back pain which started at the age of a traffic accident or fall tended to be more prolonged than that occurring in other circumstances (table II). Furthermore trauma was associated not only with low back pain but also with sciatica. This suggests that the symptoms which developed in relation to accidents were not just a trivial short term consequence of contusion. Some subjects may have exaggerated the duration of their symptoms because of associated litigation, but it is less likely that they would systematically report sciatica when none was present.

Few other studies have attempted to measure the contribution of injuries to low back pain beyond recording the proportion of cases who attribute their symptoms to a single traumatic event. In a survey of miners and other manual workers Lawrence found that the prevalence of back-hip-sciatic pain in men who reported previous back injury was $64 \%$ as compared with $35 \%$ in those with other injuries and $39 \%$ in those with no history of trauma. ${ }^{8}$ However, it is not clear exactly how injuries were defined. A case-control study of prolapsed intervertebral disc in US servicemen during World War II examined medical histories up to the time of the case's first hospital admission for a problem that might have been related to the disc disorder. ${ }^{9}$ There was no association with earlier hospital admission for trauma, but the impact of injuries may have been underestimated because by definition trauma leading to admission with overt back symptoms would have been excluded from consideration. More recently Riihimaki has reported a study of concrete reinforcement workers and maintenance house painters in Finland which showed an association between sciatic pain (defined as pain radiating to the lower limbs) during the previous 12 months and reported back injury in earlier years. ${ }^{10}$ There was no corresponding association with lumbago or non-specific back pain, and the definition of back accidents was not explicit.

From our data we estimate that a person who suffers a traffic accident or fall bad enough to require hospital admission has a $7 \%$ chance of developing low back pain as a consequence and that in one third of cases the pain will last for at least 12 months in total. It would be helpful to confirm this in a prospective study, looking in more detail at the nature of people's injuries and associated psychological stresses.

We thank the general practitioners who allowed us to approach their patients. Dr Walsh was supported by a fellowship provided by ESSO UK plc.

1 Biering-Sorensen F. A prospective study of low back pain in a general population. I. Occurrence, recurrence and aetiology. Scand f Rehabil Med 1983; 15: 71-9.

2 Frymoyer JW, Pope MH, Costanza MC, Rosen JC, Goggin JE, Wilder DG. Epidemiologic studies of low back pain. Spine 1980; 5: 419-23.

3 Magora A, Taustein I. An investigation of the problem of sick leave in the patient suffering from low back pain. Ind Med Surg 1969; 38: 398-408.

4 Peto R, Pike MC, Armitage P, et al. Design and analysis of randomized clinical trials requiring prolonged observation of each patient. II. Analysis and examples. Br $\mathcal{f}$ Cancer of each patien

5 Walsh K, Varnes N, Osmond C, Styles R, Coggon D. Occupational causes of low-back pain. Scand $\mathcal{F}$ Work

6 Walsh K, Cruddas M, Coggon D. Low back pain in eight areas of Britain. F Epidemiol Community Health 1992; 46: 227-30.

7 Walsh K, Coggon D. Reproducibility of histories of lowback pain obtained by self-administered questionnaire. Spine 1991; 16: 1075-7.

8 Lawrence JS. Rheumatism in coal miners. III. Occupational factors. Br $\mathcal{F}$ Ind Med 1955; 12: 249-61.

9 Hrubec Z, Nashold BS. Epidemiology of lumbar disc lesions in the military in World War II. Am F Epidemiol 1975; 102: $366-76$

10 Riihimaki $H$. Back pain and heavy physical work: a comparative study of concrete reinforcement workers and maintenance house painters. $\mathrm{Br} \mathcal{F}$ Ind Med 1985; 42: 226-32. 